\title{
Linx
}

Revue des linguistes de l'université Paris X Nanterre

$13 \mid 2020$

Collocations et traditions discursives

\section{Avant-propos de la direction de LINX}

\section{(2) OpenEdition \\ 1 Journals}

Electronic version

URL: http://journals.openedition.org/linx/3841

DOI: 10.4000/linx.3841

ISSN: 2118-9692

Publisher

Presses universitaires de Paris Nanterre

\section{Electronic reference}

"Avant-propos de la direction de LINX», Linx [Online], 13 | 2020, Online since 30 May 2020, connection on 25 September 2020. URL : http://journals.openedition.org/linx/3841 ; DOI : https://doi.org/

10.4000/linx.3841

This text was automatically generated on 25 September 2020 .

Département de Sciences du langage, Université Paris Ouest 


\section{Avant-propos de la direction de LINX}

1 Plusieurs linguistes des Universités de Potsdam, de Barcelone (Université Pompeu Fabra) et de Nanterre (Université de Paris Nanterre) ont animé pendant 12 ans un Collège Doctoral Franco-allemand (CDFA), financé par l'Université Franco-allemande ${ }^{1}$. La principale mission du Collège Doctoral est de permettre à des doctorants des trois universités de bénéficier de contrats doctoraux ou de courts séjours dans une des universités partenaires, et de participer chaque année à un colloque se tenant alternativement à Nanterre, Barcelone et Potsdam.

2 Ce numéro spécial de LINX accueille les Actes du colloque de doctorants qui s'est tenu le 4 juillet 2018 à l'université de Potsdam. Notre « revue des linguistes de l'université de Nanterre » a de cette manière l'opportunité de conserver et de diffuser une trace relativement récente de ce partenariat avec deux autres universités européennes².

\section{NOTES}

1. L'Université Franco-allemande (UFA) est un réseau de 194 établissements d'enseignement supérieur français et allemands. L'UFA propose en tout 185 cursus intégrés binationaux et trinationaux. Elle accueille tous les ans quelque 6400 étudiants.

2. Ce sont les professeures Gerda Hassler (Potsdam) et Danielle Leeman (Nanterre) qui ont eu, en 2007, l'initiative de ce partenariat. Gerda Hassler aura été pendant 12 ans le « pilier » du CDFA, en collaboration avec Jenny Brumme (Barcelone). A Nanterre, les successeurs de Danielle Leeman ont été Denis Le Pesant, Jean-François Jeandillou, Annie Bertin et Sabine Lehmann. 